\title{
Kinetics of carbon dioxide capture into aqueous potassium carbonate promoted by glutamic acid salt
}

\author{
Rana Esam Ahmed ${ }^{1}$, Ahmed Daham Wiheeb ${ }^{2}$, Sanaa Rabie Saleh ${ }^{3}$ \\ \{ eng.ranaesam1993@gmail.com ${ }^{1}$, chahmed@tu.edu.iq ${ }^{2}, \underline{\text { sanaarabie85@gmail.com }}{ }^{3}$ \}
}

Chemical Engineering Division, Entirety of Engineering, Tikrit University, Tikrit, Sallahaddin, Iraq, 077084825171', Chemical Engineering Division, College of Engineering, University of Diyala, Baqubah, Diyala, Iraq ${ }^{2}$, North Refinery Company, Ministry of Oil, Baiji, Sallahaddin, Iraq ${ }^{3}$

\begin{abstract}
In this research, potassium carbonate $\left(\mathrm{K}_{2} \mathrm{CO}_{3}\right)$ aquatic solution reinforcement by glutamic sour salt utilized to capturing carbon dioxide $\left(\mathrm{CO}_{2}\right)$ from Gaseous fuel in a stuffed absorber pillar at room temperature and at atmospheric pressure. Effect of glutamic sour salt concentrations on the $\mathrm{CO}_{2}$ absorption rates into carbonate solutions and glutamic acid salt were investigated. The outcome exhibit that the interaction of $\mathrm{CO}_{2}$ with $\mathrm{K}_{2} \mathrm{CO}_{3}$ aquatic solution promoted by glutamic acid salt was second-order and the rate constant $\left(\mathrm{k}_{2}\right)$ was calculated from the experiments. The interaction of $\mathrm{CO}_{2}$ with glutamic sour salt was a depiction utilized zwitterionic self-acting. The aggregate interaction pragmatic stationary $\left(\mathrm{k}_{\mathrm{ov}}\right)$ robustly augmentation with the augmentation of glutamic sour salt concentricity based on the pseudo-first-arrange regime.
\end{abstract}

Keywords: , Kinetics, $\mathrm{CO}_{2}$ capture, up taking, potassium carbonate, glutamic acid.

\section{Introduction}

The augmentation of $\mathrm{CO}_{2}$ subtract to the atmosphere is the prime benefactor to international weather variation. up taking of $\mathrm{CO}_{2}$ is one of favorable pathway to minify the $\mathrm{CO}_{2}$ subtract from scorbutic fuel- release power plants. In the bygone years, numerous manner has been offered for yet- blaze $\mathrm{CO}_{2}$ up take [1-2]. sucking with chemical aqueous solution is the extreme vastly elaborate and handy picking to considerable-calibrate enforcement . The capturing of $\mathrm{CO}_{2}$ with amines or carbonate aquatic solution have obtained spread alertness inter alia absorptive [3]. Hot potassium carbonate process, recognized as Benfield process, has been hired tardily for curing sour gas influx for plentiful years [4]. In rapprochement to the benchmark amine-based aquatic solutions in private monoethanolamine (MEA)), potassium carbonate has a grist of trait-like little of up taking, little price, minus virulent and aquatic solutions minus, no thermal and oxidative ebb, outwardly the figuration of heat-firm pressing [2]. The confront correlating with hire $\mathrm{K}_{2} \mathrm{CO}_{3}$ is the tardy interaction rate of up taking, bring about in pauper $\mathrm{CO}_{2}$ mass transfer [5-6]. Furthermore, for yet- blaze uptake, the up taking process is wanted to turn on at flue gas conditions like naturalistic pressure and comparatively little temperature [7]. The up taking rate would be worst than that in Benfield process . subsequently, the potency of rate growing by the use of developer is of worthy avails to recover the $\mathrm{CO}_{2}$ mass convey rates. Lately, piperazine has been inspected vastly in carbonate aquatic solutions and theorize as a favorable developer inter alia the amine set in order to of prompt up taking rate and adequate evenness demeanor [8]. however although, for yet-blaze flue gas curing in the extremely oxygenated milieu and elevation temperature restoration, amines similar MEA and piperazine might not be of considerable benefit in order to oxidative 
and thermal retrogression, elevation dispersal, elevation energy request, attrition and ecological influence [9-10]. Lately, alkaline salts of amino sours have been offered as adequate elect aquatic solutions for $\mathrm{CO}_{2}$ up taking in order having congruent handy set as alknolamines. presently, there is a freshen benefit in the hire of amino sours salt for $\mathrm{CO}_{2}$ up take from flue gas influx. comparatively studies once upon a time announce concerning the up taking of $\mathrm{CO}_{2}$ in diverse amino sour salt aquatic solutions like potassium salts of glycine, taurine, threonine, sarcosine, proline and alanine [13]. Van Holst et al. [16] candida ridding treatise for the kinetics of $\mathrm{CO}_{2}$ up taking into aquatic solutions of sundry amino sour salts. The salts of sarcosine and proline with altitude interaction rate stationary at $\mathrm{CO}_{2}$ have been announcing in recently viewed [14]. Otherwise, the interaction of $\mathrm{CO}_{2}$ with diverse alkaline salts of amino sours has been qualified by zwitterionic mechanization and has been taken apart hire pseudo-first seek [15].

In this work, Glutamic acid salt has been offered as a rate- developer in carbonate aquatic solutions. Glutamic sour salt embarrasses a incipient amino bracket in an addendum to a two carboxyl groups in its side chain can be foreseeable to interact with $\mathrm{CO}_{2}$ in a analogous modality with an amine. Its reactivity and strength are prospective analogous to amines of the united layers and simple rejuvenation of absorptive is also prospective . however although, its kinetic reference in this scope is exceptional in urbanity and poverty to be evidence. In the sitting work, the up taking rate of $\mathrm{CO}_{2}$ into glutamic sour salt- corroborative aquatic carbonate solution were utterly hiring a Packed bed pillar at $30 \mathrm{wt} . \% \mathrm{~K}_{2} \mathrm{CO}_{3}$.

\section{Reaction mechanism}

The average of interaction is a remarkable laborer in remission the bulk of the pillar and the magnitude of solvent and subsequently minify the capital charges of the absorber, whilst a weakened value of acid dissociation constant $(\mathrm{Pka})$ is requisite to minify the energy poverty for $\mathrm{CO}_{2}$ restoration [11].

\subsection{Hydration of $\mathrm{CO}_{2}$ into an aquatic solution of $\mathrm{K}_{2} \mathrm{CO}_{3}$}

The interactions of $\mathrm{CO}_{2}$ with an aquatic solution of $\mathrm{K}_{2} \mathrm{CO}_{3}$ can be described as follows [17]:

$$
\begin{aligned}
& \mathrm{CO}_{2}+\mathrm{OH}^{-} \stackrel{\mathrm{k}_{\mathrm{OH}^{-}}}{\Longleftrightarrow} \mathrm{HCO}_{3}^{-} \\
& \mathrm{CO}_{2}+\mathrm{H}_{2} \mathrm{O} \stackrel{\mathrm{k}_{\mathrm{H}_{2} \mathrm{O}}}{\Longleftrightarrow} \mathrm{HCO}_{3}^{-}+\mathrm{H}^{+}
\end{aligned}
$$

In requisite aquatic solutions $\left(\mathrm{pH}>8\right.$ ), the interaction of $\mathrm{CO}_{2}$ with $\mathrm{H}_{2} \mathrm{O}$ (equation (2) can be ignored . As a result, the reaction of $\mathrm{CO}_{2}$ with $\mathrm{OH}^{-}$(equation (1)) is the victorious interaction and the average- shackle interaction in requisite aquatic solution . The average of fore reaction qualified by equation (1) is given by [18]:

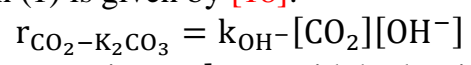

the second seek average stationary $\mathbf{k}_{\mathbf{O H}}{ }^{-}$with hydroxide ion is fully realize in the typecast [19, 20] and can portend as a duty of ionic intensity .

\subsection{Reaction of $\mathrm{CO}_{2}$ with Glutamic acid salt}


The molecular structure of Glutamic acid $\left(\mathrm{C}_{5} \mathrm{H}_{9} \mathrm{O}_{4} \mathrm{~N}\right)$ can be perform as [HOOC$\left.\mathrm{CH}\left(\mathrm{NH}_{2}\right)-\left(\mathrm{CH}_{2}\right)_{2}-\mathrm{COOH}\right]$ with two carboxyl set $\left({ }^{-} \mathrm{COOH}\right)$ and one (mainly) amino set $\left({ }^{-} \mathrm{NH}_{2}\right)$. subsequently, glutamic sour would be in prospect to interact with $\mathrm{CO}_{2}$ by its mainly amino set. The interaction of $\mathrm{CO}_{2}$ with amino sour is a qualified setup on zwitterionic mechanization [21]. Deprotonation of the zwitterionic amino sours is carried out by joining a twice molar compensate of a potent rule like potassium hydroxide $(\mathrm{KOH})$ which perfectly untangle in water [22]. This deprotonation follows in his footsteps is essential due to make the amino set interact with $\mathrm{CO}_{2}$.

Many studies [31-33] have been offered that the interaction $\mathrm{CO}_{2}$ and the deprotonated amino sours income utilizing a zwitterionic carbamate moderate :

$-\mathrm{OOC}-\mathrm{CH}\left(\mathrm{NH}_{3}^{+}\right)-\left(\mathrm{CH}_{2}\right)_{2}-\mathrm{COO}^{-}+\mathrm{CO}_{2} \underset{\mathrm{k}_{-1}}{\stackrel{\mathrm{k}_{2}}{\leftrightarrow}}-{ }^{-} \mathrm{OOC}-\mathrm{CH}(\mathrm{NH})\left(\mathrm{COO}^{-}\right)-\left(\mathrm{CH}_{2}\right)_{2}-\mathrm{COO}^{-}$

Where: $\mathrm{k}_{2}$, is the forward second seek average stationary evenness and $\mathrm{k}_{-1}$, is the zwitterion mechanization average stationary.

The above interaction is follow up by the elimination of a proton from the zwitterionic carbamate hiring any rule $\mathrm{B}$, to form an indifferent carbamate (the base-catalyzed deprotonation) as offered in neutralization (5). In this labor, water $\left(\mathrm{H}_{2} \mathrm{O}\right)$, carbonate ions $\left(\mathrm{CO}_{3}{ }^{-}\right)$, bicarbonate ions $\left(\mathrm{HCO}_{3}{ }^{-}\right)$and the deprotonated amino sour (AA) all can performance as rule [26].

$-\mathrm{OOC}-\mathrm{CH}(\mathrm{NH})\left(\mathrm{COO}^{-}\right)-\left(\mathrm{CH}_{2}\right)_{2}-\mathrm{COO}^{-}+\mathrm{B} \underset{\mathrm{k}_{-\mathrm{b}}}{\stackrel{\mathrm{k}_{\mathrm{b}}}{\leftrightarrow}}-\mathrm{OOC}-\mathrm{CH}(\mathrm{N})\left(\mathrm{COO}^{-}\right)-\left(\mathrm{CH}_{2}\right)_{2}-\mathrm{COO}^{-}+\mathrm{BH}^{+}$

Where: $\mathrm{k}_{\mathrm{b}}$ : kinetic constant represents deprotonation of the zwitterions.

acting as if a quasi- stationary-case constrain for the zwitterion concentricity and the second proton relocate interaction can be reckoned not to reverse, (the average of the interaction of $\mathrm{CO}_{2}$ in an aquatic glutamic acid salt aquatic solution can be in any event express as:

$$
\begin{aligned}
& \mathrm{r}_{\mathrm{CO}_{2}, \mathrm{GLu}_{\mathrm{s}}}=-\frac{\mathrm{k}_{2}\left[\mathrm{CO}_{2}\right][\mathrm{AA}]}{1+\frac{\mathrm{k}_{-1}}{\sum \mathrm{k}_{\mathrm{b}}[\mathrm{B}]}}
\end{aligned}
$$

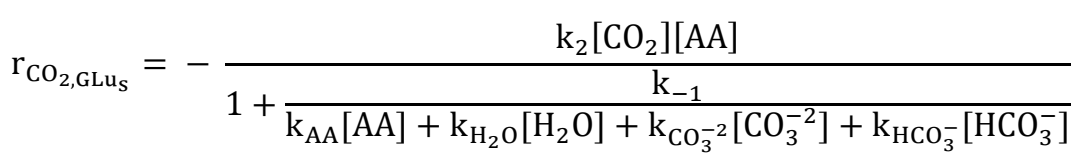

Two prime similar stance $\frac{\mathbf{k}_{-1}}{\sum \mathbf{k}_{\mathbf{b}}[\mathbf{B}]} \ll 1$ and $\frac{\mathbf{k}_{-1}}{\sum \mathbf{k}_{\mathbf{b}}[\mathbf{B}]} \gg 1$ are considered simplifying the interaction kinetic paradigm of amino sour corn, which is wholly qualified in letters [11, 23,27]. The preceding outcome in modest second-seek kinetics. The outcome in a ganglion interaction average express (e.g. third-seek kinetics if the deprotonation is fundamentally by amine). mainly amines like MEA ordinarily interact with $\mathrm{CO}_{2}$ next a second seek interaction 
kinetics which wherewithal that the deprotonation of the zwitterion is comparatively quickly when contrast to the invert average of $\mathrm{CO}_{2}$ and first amines. Subsequently, the confined stipulation, $\frac{\mathbf{k}_{-1}}{\sum \mathbf{k}_{\mathbf{b}}[\mathbf{B}]} \ll 1$ (the average of zwitterion deprotonation is prompt than the invert average of $\mathrm{CO}_{2}$ and glutamic acid) leads to a straightforward interaction average express as follows $[11,24]$ :

$$
\mathrm{r}_{\mathrm{CO}_{2}, \mathrm{GLu}_{\mathrm{s}}}=\mathrm{k}_{2}\left[\mathrm{CO}_{2}\right][\mathrm{Glus}]
$$

Indicating that the interaction is the first seek of jointly the $\mathrm{CO}_{2}$ and the amino acid corn, and hence, totally of the second seek.

\subsection{Interaction rate for $\mathrm{CO}_{2}$ absorption into the $\mathrm{K}_{2} \mathrm{CO}_{3}$ aquatic solution with a glutamic acid salt}

When aquatic $\mathrm{K}_{2} \mathrm{CO}_{3}$ promoted by glutamic acid salt, it is fundamental to gather together $\mathrm{CO}_{2}$ hydration with $\mathrm{OH}^{-}$and zwitterionic interaction with glutamic acid into reckoning in the translation of the up taking average tests. The $\mathrm{CO}_{2}$ up taking average can be offered by [21]:

$$
\mathrm{r}_{\mathrm{ov}}=\mathrm{k}_{\mathrm{ov}}\left[\mathrm{CO}_{2}\right]=\mathrm{r}_{\mathrm{CO}_{2} \cdot \mathrm{K}_{2} \mathrm{CO}_{3}}+\mathrm{r}_{\mathrm{CO}_{2}, \mathrm{GLu}_{\mathrm{s}}}
$$

Where: $\mathrm{k}_{\mathrm{ov}}$, is the inclusive pseudo-first-seek interaction average stationary.

subrogate the interaction average from equation (3) and equation (8) into equation. (9), $\mathrm{k}_{\mathrm{ov}}$ can then be expressed as [17]:

$$
\begin{aligned}
& \mathrm{r}_{\mathrm{ov}}=\mathrm{k}_{\mathrm{OH}^{-}}\left[\mathrm{CO}_{2}\right]\left[\mathrm{OH}^{-}\right]+\mathrm{k}_{2}\left[\mathrm{CO}_{2}\right][\text { Glus }] \\
& \left.\mathrm{k}_{\mathrm{ov}}=\mathrm{k}_{\mathrm{OH}^{-}}\left[\mathrm{OH}^{-}\right]+\mathrm{k}_{2} \text { Glus }\right]
\end{aligned}
$$




\section{Experimental work}

\subsection{Chemicals and tools}

In this treatise, $\mathrm{K}_{2} \mathrm{CO}_{3}(99 \%)$ and Glutamic acid (Glu) were procured from Scharlau/ Spain. Potassium hydroxide $(\mathrm{KOH})$ with $85 \%$ was purchased from Fluka. Hydrochloric acid $(\mathrm{HCl})$ with $37 \%$ pureness procured from Merck Germany . $\mathrm{CO}_{2}(99.99 \%)$ and $\mathrm{N}_{2}(99.99 \%)$ used in the absorption tests were together furnished from SDI Samarra, Iraq. Stuffed pillar synthetic from glazier with an interior diameter of $4.2 \mathrm{~cm}$ and elevation of $140 \mathrm{~cm}$ was hired in the up taking tests of $\mathrm{CO}_{2}$. The stuffing elevation interior the pillar was $88 \mathrm{~cm}$ with a stuffing substance of attaining gang $(0.3 \mathrm{~cm}$ extrinsic diameter $)$. whilst, glazier receptacle of $100 \mathrm{ml}$ was hired in the desorption tests of $\mathrm{CO}_{2}$. For perfect allocation of aquatic solutions during the stuffing, fluid dispenser was conformed in the elevation fraction . The gas blend $\left(\mathrm{CO}_{2}\right.$ and $\left.\mathrm{N}_{2}\right)$ pushed during to the stuffed pillar through the cribriform dish stationary in under most of the pillar to shore the stuffing substances . However although, a rotameters linked with gas rollers and fluid pump were hired to take control of the gas flowing average and solvent flowing average, respectively.

\subsection{Experimental procedure}

$\mathrm{CO}_{2}$ up taking tests brought about by following our previous experimental procedure [2]. Figure 1 exhibit the empirical intrigue of the up taking process . The $\mathrm{CO}_{2}$ capacity was computed in the existent aquatic solution paradigm possessed at stationary times utilizing the procedure of acidification titration (Chittick device) [2]. Pending the mensuration of $\mathrm{CO}_{2}$ loading, $1 \mathrm{M} \mathrm{HCl}$ was a supplement to the aquatic solution paradigm till changeful the evidence tint [1]. So, $\mathrm{CO}_{2}$ gas was emitted in order to the neutralization interaction and gather in a surpass roller encompass the offer tint aquatic solution . Overabundant quantity of $\mathrm{HCl}$ was a supplement to assure the perfectly emitted of $\mathrm{CO}_{2}$. The $\mathrm{CO}_{2}$ loading expressed as mol $\mathrm{CO}_{2}$ per mol aquatic solution was computed by rebating the complete magnitude of $\mathrm{HCl}$ from the magnitude of $\mathrm{CO}_{2}$, as an offering in eq. (12) :

$$
\alpha_{\mathrm{CO}_{2}}=\frac{\left(\mathrm{V}_{\mathrm{CO}_{2}}-\mathrm{V}_{\mathrm{HCl}}\right) \times(\mathrm{P}) \times(273 \mathrm{~K})}{\mathrm{C}_{\text {solution }} \times \mathrm{V}_{1} \times \mathrm{A} \times(760 \mathrm{mmHg}) \times(\mathrm{T})}
$$

Where $\alpha_{\mathrm{CO}_{2}}$ : $\mathrm{CO}_{2}$ loading (mole $\mathrm{CO}_{2} /$ mole solvent), $\mathrm{V}_{\mathrm{CO}_{2}}$ is the magnitude of $\mathrm{CO}_{2}$ composed in the graduated gas cylinder $(\mathrm{ml}), \mathrm{V}_{\mathrm{HCl}}$ : is the magnitude of $\mathrm{HCl}$ adjust midst the titration process $(\mathrm{ml}), \mathrm{T}$ : is the laboring temperature $(\mathrm{K}), \mathrm{P}$ : is the atmospheric pressure $(\mathrm{mmHg}), \mathrm{V}_{1}:$ is the magnitude of aquatic solution paradigm $(\mathrm{ml})$ and $\mathrm{A}$ : is the convertibility factor $(22.41$ $\mathrm{L} / \mathrm{mol}$ ). Then the equipoise was proven one-day frequent readings of $\mathrm{pH}$ exhibit just a trivial variance. Next, pass into the first hour of up taking the test, $\mathrm{CO}_{2}$ loading was frequent per 15 $\min$. 


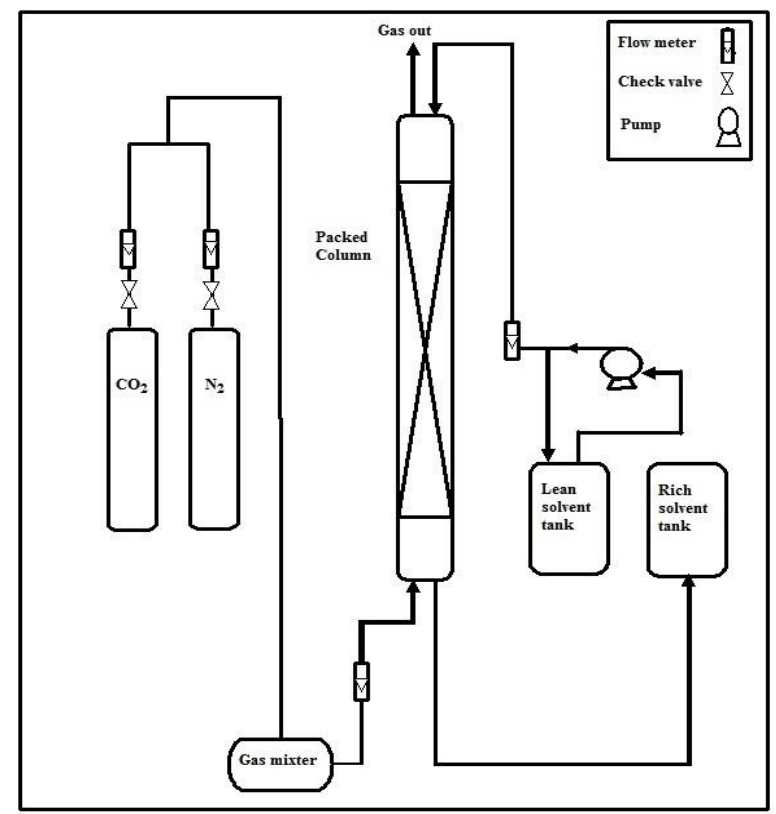

Fig. 1. Silhouette of the up taking process.

The aquatic solution up taking process was deem following up before time authenticated labor [1]. Figure 2 offers the test put-up of the rejuvenation process. The efficiency of rejuvenation can be calculated using equation (13) [29].

Regeneration efficiency $=\left(1-\left(\alpha_{\mathrm{CO}_{2} \text { lean }} / \alpha_{\mathrm{CO}_{2 \text { rich }}}\right)\right) \times 100$

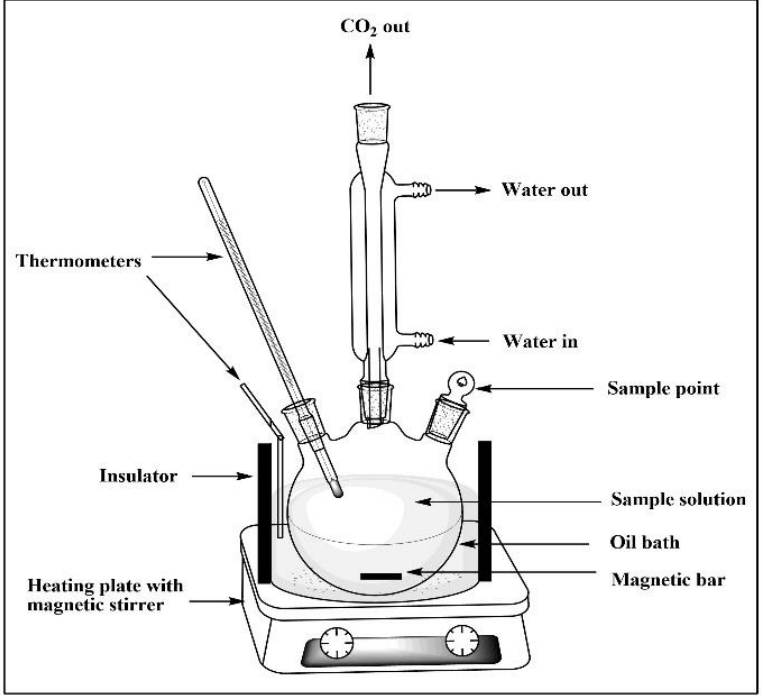

Fig. 2. Silhouette of the rejuvenation process. 


\subsection{Kinetics measurement}

Reaction rate is calculated from the change of $\mathrm{CO}_{2}$ concentration obtained from experimental results with absorption time $\left(\mathrm{d}\left[\mathrm{CO}_{2}\right] / \mathrm{dt}\right)$. After that, the calculated reaction rates were plotted against $\mathrm{CO}_{2}$ concentrations to prove the order of the reaction from the curve shape. The $\mathrm{k}_{\mathrm{ov}}$ was calculated from equation (14):

$$
\mathrm{r}_{\mathrm{ov}}=\mathrm{k}_{\mathrm{ov}}\left[\mathrm{CO}_{2}\right]
$$

Where: $\mathrm{r}_{\mathrm{ov}}$ : $\mathrm{CO}_{2}$ kinetic average $\left(\mathrm{mol} \mathrm{L}^{-1} \mathrm{~s}^{-1}\right), \mathrm{k}_{\mathrm{ov}}$ : pseudo-first-rank interaction average stationary $\left(\mathrm{s}^{-1}\right),\left[\mathrm{CO}_{2}\right]$ : concentricity of $\mathrm{CO}_{2},\left(\mathrm{~mol} \mathrm{~L}^{-1}\right)$. Then, the average constants $\mathrm{k}_{\mathrm{OH}^{-}}$and $\mathrm{k}_{2}$ were calculated from the experimental results using equation (15):

$$
\left.\mathrm{k}_{\mathrm{ov}}=\mathrm{k}_{\mathrm{OH}^{-}}\left[\mathrm{OH}^{-}\right]+\mathrm{k}_{2} \text { [Glus }\right]
$$

Where: $\mathrm{k}_{\mathrm{OH}^{-}}$and $\mathrm{k}_{2}$ are the rate constants $\left(\mathrm{L} \mathrm{mol}^{-1} \mathrm{~s}^{-1}\right),\left[\mathrm{OH}^{-}\right]$, [Glus] are the molar concentrations $\left(\mathrm{mol} \mathrm{L}^{-1}\right)$. deeming the donating of average enhancement and the addendum of glutamic acid salt, the interaction average stationary for $\mathrm{Glu}_{\mathrm{s}}, \mathbf{k}_{\mathbf{o v}}^{\prime}$, is realized as follow up :

$$
\mathrm{k}_{\mathrm{ov}}^{\prime}=\mathrm{k}_{\mathrm{ov}}-\mathrm{k}_{\mathrm{OH}^{-}}\left[\mathrm{OH}^{-}\right]
$$

The interaction average $\left(\mathrm{k}_{\mathrm{ov}}^{\prime}\right)$ rise linearly with $\left[\mathrm{Glu}_{\mathrm{s}}\right]$. The slopes of this line were represented the rate constant $\left(\mathrm{kglu}_{\mathrm{gl}}\right)$.

\section{Results and discussion}

Figure 3. appears the affluent and scrawny $\mathrm{CO}_{2}$ tautology for $\mathrm{K}_{2} \mathrm{CO}_{3}$ aquatic solution and Glus at $1 \mathrm{M}$ concentricity, air pressure and temperature. It very well may be noticed that Glus has better $\mathrm{CO}_{2}$ affluent tautology analyzed than various solvents. whilst, the $\mathrm{CO}_{2}$ scrawny tautology of Glus was lower than various solvents. These outcomes can be clarified that the absorption tautology of $\mathrm{CO} 2$ was diminished with increasing carbon series length thanks to a rise in molecular weight which suggests that the answer contains a lower molecule of the absorbent [30,31]. The $\mathrm{CO}_{2}$ tautology for $\mathrm{K}_{2} \mathrm{CO}_{3}$ and Glus appears to be acceptable concurrence with aftereffects of past work $[6,32]$. The low $\mathrm{CO}_{2}$ tautology for $\mathrm{K}_{2} \mathrm{CO}_{3}$ is thanks to the cumbersome response with $\mathrm{CO}_{2}$. While the high $\mathrm{CO}_{2}$ scrawny tautology thanks to the troublesome crumbling of the bonds and discharged $\mathrm{CO}_{2}$ [23]. Likewise, it is seen that $\mathrm{K}_{2} \mathrm{CO}_{3}+$ Glus dissolvable have lower $\mathrm{CO}_{2}$ scrawny tautology. The assimilation of $\mathrm{CO}_{2}$ in $\mathrm{K}_{2} \mathrm{CO}_{3}$ is obviously improved when promoted with a few measures of amino acid salts. This was because of the reduction of the carbamate stability which prompts increment the $\mathrm{CO}_{2}$ tautology in affluent dissolvable as a result of the expansion in the substituent attached to nitrogen particle[33]. 


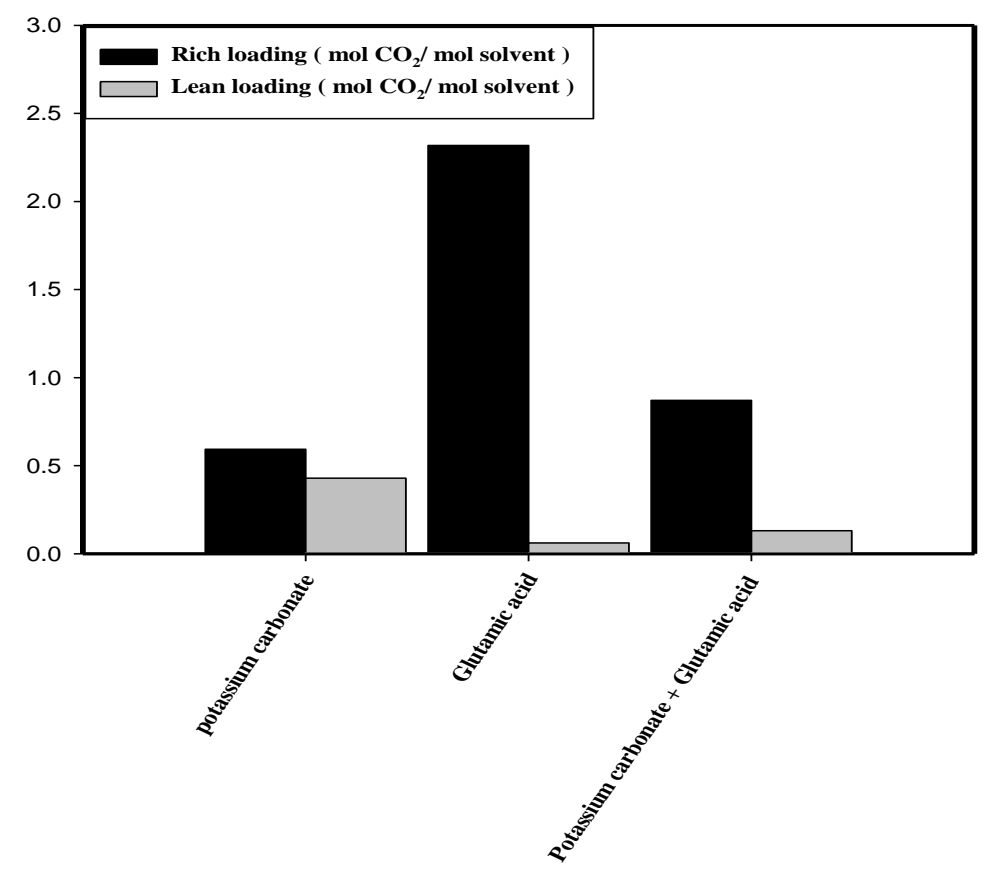

Fig. 3. Rich and lean $\mathrm{CO}_{2}$ loading of $\mathrm{K}_{2} \mathrm{CO}_{3}$, $\mathrm{Glu}_{\mathrm{s}}$, and $\mathrm{K}_{2} \mathrm{CO}_{3}+\mathrm{Glu}_{\mathrm{s}}$ solvents at atmospheric pressure, $298 \mathrm{~K}$ and $15 \% \mathrm{CO}_{2}$ balanced with $\mathrm{N}_{2}$.

The identical revelation competence for every solvent at desorption temperature of 363 $\mathrm{K}$ is introduced in Figure 4. It is obviously observed that $\mathrm{K}_{2} \mathrm{CO}_{3}$ has the least recovery effectiveness of all the examined solvents. While Glus offered the very best regeneration performance contrasted with different solvents. Glus has kept up the very best regeneration efficiency thanks to discharge $\mathrm{CO}_{2}$ from carbamate in all the single solvents was higher contrasted and bicarbonate in Glus. What's more, Glus has molecular structure that makes it effectively recover and acquaint incredible debasement obstruction examination with other solvents $[34,35]$. the rise of bicarbonate concentration profoundly influences the $\mathrm{CO}_{2}$ scrawny tautology thanks to the simplest heat breaking of bicarbonate than carbamate. Including of Glus increment the regeneration competence above that of other promoters as indicated by their tendency and the mix impact with $\mathrm{K}_{2} \mathrm{CO}_{3}$. Glus kept the very best regeneration efficiency thanks to the molecular structure, which were handily regenerated and introduced great degradation resistance, as compared to the opposite solvent. While, other solvent required a high measure of vitality for revelation $[26,36]$. 


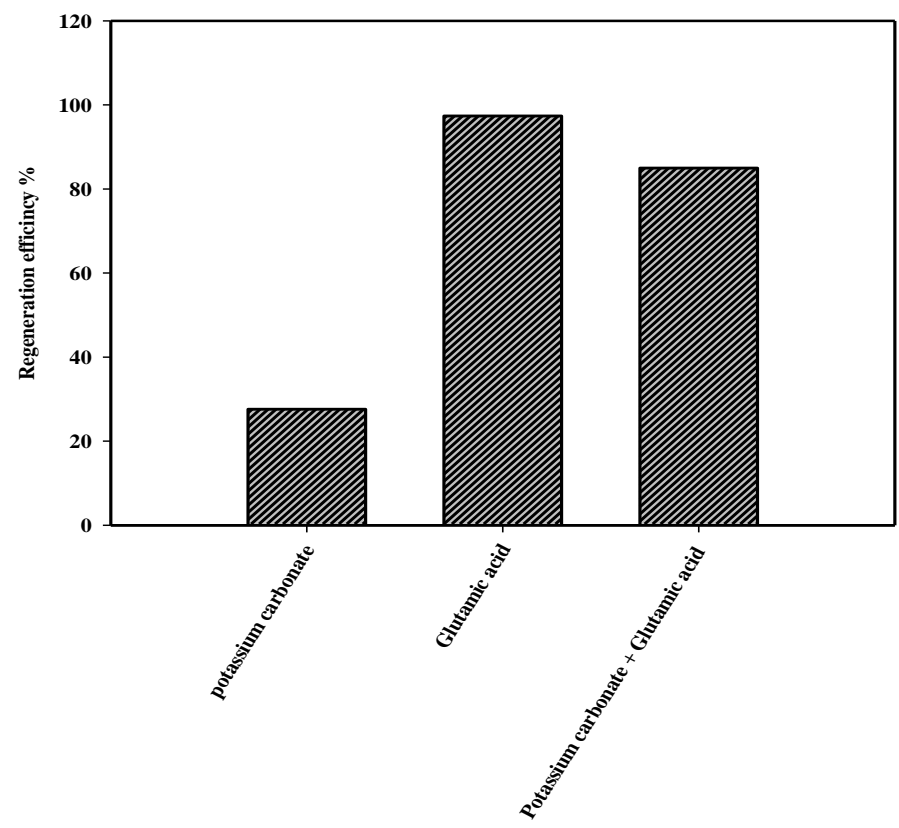

Fig. 4. Regeneration efficiency of $\mathrm{K}_{2} \mathrm{CO}_{3}, \mathrm{Glu}_{\mathrm{s}}$, and $\mathrm{K}_{2} \mathrm{CO}_{3}+\mathrm{Glu}_{\mathrm{s}}$ solvents at atmospheric pressure, $298 \mathrm{~K}$ and desorption temperature of $363 \mathrm{~K}$.

Figure 5 presents the rate reaction of $\mathrm{CO}_{2}$ in $\mathrm{K}_{2} \mathrm{CO}_{3}$ aquatic solution advanced by 15 vol.\% of Glus. It tends to be seen that the relationship was nonlinear and expanding the response rate with the concentration of $\mathrm{CO} 2$ reactant. The $\mathrm{R}^{2}$ from the bent fitting was equivalent to 1 with a second request connection between the rate response of $\mathrm{CO}_{2}$ with dissolvable concentrations. In this manner, the reaction is second order. Two potential reasons were considered for glutamic corrosive to be the best advertiser in $\mathrm{K}_{2} \mathrm{CO}_{3}$ for $\mathrm{CO}_{2}$ retention. To begin with, the glutamic acidulous contains a principally amino gathering which has a quick response rate with $\mathrm{CO}_{2}[19$, 20]. Second, the zwitterion response instrument is commonly acknowledged and the carbamate development is a crucial step. 


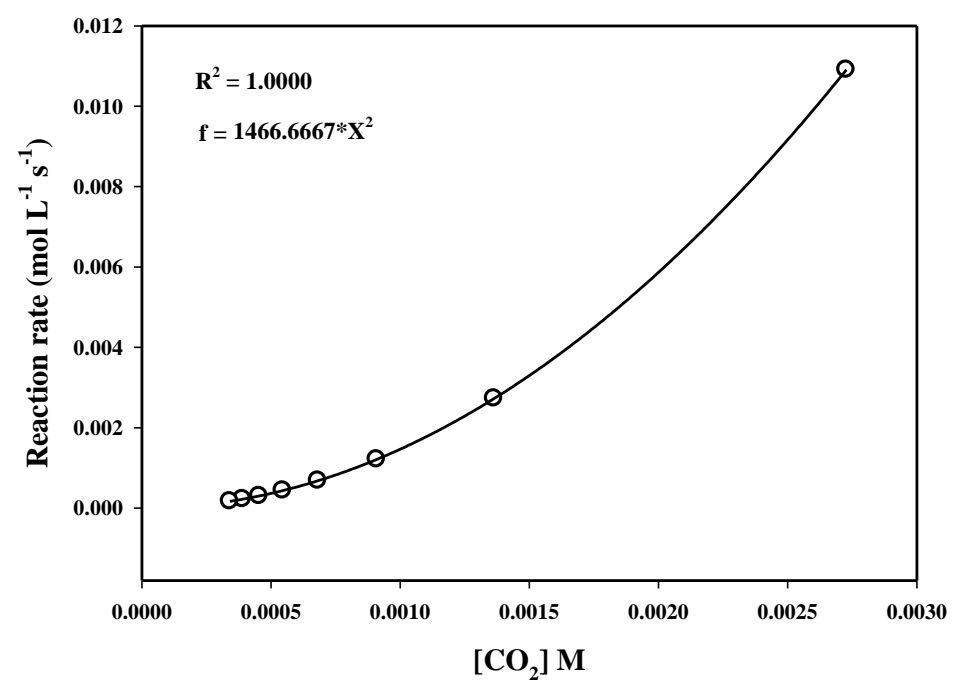

Fig. 5. Rate reaction of $\mathrm{CO}_{2}$ with $\mathrm{K}_{2} \mathrm{CO}_{3}$ solution promoted by 15 vol.\% of $\mathrm{Glu}_{\mathrm{s}}$.

Figure 6 presents the impact of absorption time on the general reaction rate constant ( kov) determined from condition (14) for $\mathrm{K}_{2} \mathrm{CO}_{3}$ solution advanced by 15 vol.\% Glus. It very well may be seen that the kov dropped pointedly. Toward the start of absorption, concentrations of hydroxide ion and Glus have been at a significant level, and afterward, quick absorption rates were found. With increasing the absorption time, the concentration of $\mathrm{HCO}_{3}^{-}$and deprotonated zwitterions from Glus in solution expanded and afterward the concentration of hydroxide ion and dynamic Glus segment diminished [21,37]. 


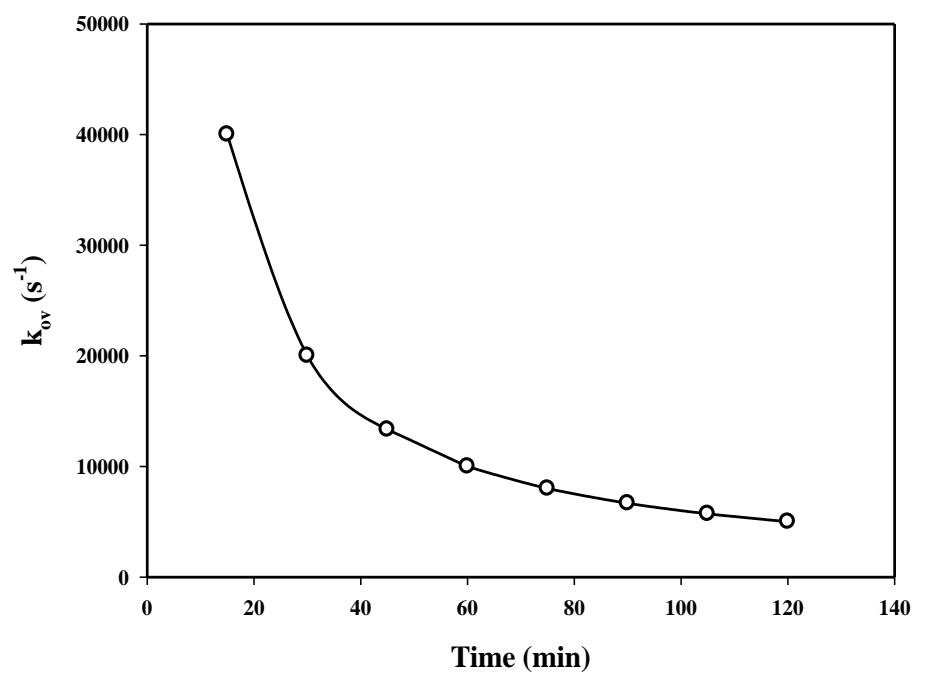

Fig. 6. Overall reaction rate constant with absorption time for $\mathrm{K}_{2} \mathrm{CO}_{3}$ solution promoted by $15 \mathrm{vol} . \%$ of $\mathrm{Glu}_{\mathrm{s}}$ at $298 \mathrm{~K}$.

In light of the pseudo-first-request system and zwitterionic component for the response of $\mathrm{CO}_{2}$ and glutamic acidulous, the second-order response rate consistent, $\mathrm{k}_{2}$, (determined from condition (15), is $21282.16 \mathrm{~L}$ mol-1 s-1 and the second-order response rate steady with hydroxide particle, (determined from condition (15), is $7265.6 \mathrm{~L} \mathrm{mol-1} \mathrm{s-1.} \mathrm{The} \mathrm{low} \mathrm{warmth} \mathrm{of}$ absorption related with $\mathrm{K}_{2} \mathrm{CO}_{3}$ arrangement and $\mathrm{K} 2 \mathrm{CO} 3+$ Glus frameworks might decrease vitality costs in $\mathrm{CO}_{2}$ catch process. Higher $\mathrm{CO} 2$ tautology and quick retention energy demonstrate that this amino acidulous can be a decent alternative solvent [1]. An examination between rate constants of varied promoters at $1 \mathrm{M}$ and $25 \mathrm{oC}$ appears in Table 1 . The way that the rate consistent of Glus is higher than those of some ordinary amines, yet lower than those of the cyclic diamine PZ. Notwithstanding Glus offering lower rate advancement when contrasted with PZ, glutamic acidulous is less harmful and earth amicable and in this way might be considered as a promising advertiser for carbonate-based solvents [17, 38].

Table 1. Rate constants of $\mathrm{K}_{2} \mathrm{CO}_{3}$ solution with various promoters at $1 \mathrm{M}$ and $298 \mathrm{~K}$.

\begin{tabular}{lcc}
\hline Solvent & Rate constant $\left(\mathbf{s}^{\mathbf{1}}\right)$ & Ref. \\
\hline $\mathrm{K}_{2} \mathrm{CO}_{3}+\mathrm{MEA}$ & 5900 & {$[47]$} \\
$\mathrm{K}_{2} \mathrm{CO}_{3}+\mathrm{TEA}$ & 50 & {$[48]$} \\
$\mathrm{K}_{2} \mathrm{CO}_{3}+$ MDEA & 4.4 & {$[51]$} \\
$\mathrm{K}_{2} \mathrm{CO}_{3}+$ Piperazine & 53700 & {$[49]$} \\
$\mathrm{K}_{2} \mathrm{CO}_{3}+\mathrm{DEA}$ & 1300 & {$[48]$} \\
$\mathrm{K}_{2} \mathrm{CO}_{3}+$ Boric acid & 45 & {$[50]$} \\
$\mathrm{K}_{2} \mathrm{CO}_{3}+$ Glutamic acid & 24541.48 & This work \\
\hline
\end{tabular}




\section{Conclusions}

The kinetics of $\mathrm{CO}_{2}$ response with $\mathrm{K}_{2} \mathrm{CO}_{3}$ solution promoted by 15 vol.\% of Glus were explored in a packed bed absorber at room temperature. The $\mathrm{CO}_{2}$ absorption rate of $\mathrm{K}_{2} \mathrm{CO}_{3}$ solution was upgraded by including a modest quantity of Glus. The pseudo-first-order system and zwitterionic component were applied to portray the energy of $\mathrm{CO}_{2}$ connection with $\mathrm{K}_{2} \mathrm{CO}_{3}$ arrangement advanced by 15 vol.\% of Glus. It was discovered that the response is a second order. The got second-order response rate consistent $\left(\mathrm{k}_{2}\right)$ is $21282.16 \mathrm{~L} \mathrm{mol-1} \mathrm{s-1}$ and the second-order response rate steady with hydroxide ion is seen as $7265.595 \mathrm{~L}$ mol-1 s-1. Glus contains a fundamentally amino gathering which has been appeared to have a quick reaction rate with $\mathrm{CO}_{2}$. Glus is a promising advertiser to $\mathrm{K}_{2} \mathrm{CO}_{3}$ solution for catching of $\mathrm{CO}_{2}$.

\section{Acknowledgments}

The authors thank the Division of Chemical Engineering/College of Engineering/Tikrit University for their help in this exploration.

\section{References}

[1] Wiheeb, A., Shakir, S., Ahmed, M. \& Rajab, E. Experimental investigation of carbon dioxide capturing into aqueous carbonate solution promoted by alkanolamine in a packed absorber. $20181 \mathrm{st}$ International Scientific Conference of Engineering Sciences-3rd Scientific Conference of Engineering Science (ISCES), 2018. IEEE, 152-156.

[2] Ahmed, R. \& Wiheeb, A. 2019. Enhancement of carbon dioxide absorption into aqueous potassium carbonate by adding amino acid salts. Materials Today: Proceedings.

[3] Wiheeb, A. D., Ahmad, M. A., Murat, M. N., Kim, J.-S. \& Othman, M. R. 2015. Surface affinity and interdiffusivity of carbon dioxide inside hydrotalcite- silica micropores: $\mathrm{CO}_{2}$ interdiffusion inside ht- si micropores. Journal of Porous Media, 18.

[4] Cullinane, J. T. \& Rochelle, G. T. 2006. Kinetics of carbon dioxide absorption into aqueous potassium carbonate and piperazine. Industrial \& Engineering Chemistry Research, 45, 2531-2545.

[5] Rochelle, G. T., Sexton, A., Davis, J., Hilliard, M., Xu, Q., Van Wagener, D. \& Plaza, J. M. 2007. $\mathrm{CO}_{2}$ capture by absorption with potassium carbonate. University Of Texas At Austin.

[6] Hu, G. 2018. Novel promoters for carbon dioxide absorption in potassium carbonate solutions. [7] Mumford, K. A., Smith, K. H., Anderson, C. J., Shen, S., Tao, W., Suryaputradinata, Y. A., Qader, A., Hooper, B., Innocenzi, R. A. \& Kentish, S. E. 2011. Post-combustion capture of $\mathrm{CO}_{2}$ : results from the solvent absorption capture plant at Hazelwood power station using potassium carbonate solvent. Energy \& fuels, 26, 138-146.

[8] Cullinane, J. T. 2002. Carbon dioxide absorption in aqueous mixtures of potassium carbonate and piperazine. University of Texas at Austin.

[9] Holst, J. V., Kersten, S. R. \& Hogendoorn, K. J. 2008. Physiochemical properties of several aqueous potassium amino acid salts. Journal of Chemical \& Engineering Data, 53, 1286-1291.

[10] Supap, T., Idem, R., Tontiwachwuthikul, P. \& SAIWAN, C. 2006. Analysis of monoethanolamine and its oxidative degradation products during $\mathrm{CO} 2$ absorption from flue gases: A comparative study of GC-MS, HPLC-RID, and CE-DAD analytical techniques and possible optimum combinations. Industrial \& Engineering Chemistry Research, 45, 2437-2451.

[11] Van Holst, J., Versteeg, G., Brilman, D. W. F. \& Hogendoorn, J. 2009. Kinetic study of $\mathrm{CO}_{2}$ with various amino acid salts in aqueous solution. Chemical Engineering Science, 64, 59-68.

[12] M. Kim, H. Song, M. Lee, H. Jo, J. Park, Kinetics and steric hindrance effects of carbon dioxide absorption into aqueous potassium alaninate solutions, Ind. Eng. Chem. Res. 51 (2012) 2570-2577. 
[13] Lim, J.-A., Kim, D. H., Yoon, Y., Jeong, S. K., Park, K. T. \& Nam, S. C. 2012. Absorption of $\mathrm{CO}_{2}$ into aqueous potassium salt solutions of L-alanine and L-proline. Energy \& fuels, 26, 3910-3918. [14] K. Simons, W. Brilman, H. Mengers, K. Nijmeijer, M. Wessling, Kinetics of $\mathrm{CO}_{2}$ absorption in aqueous sarcosine salt solutions: influence of concentration, temperature, and $\mathrm{CO}_{2}$ loading, Ind. Eng. Chem. Res. 49 (2010) 9693-9702.

[15] A.F. Portugal, F.D. Magalhəes, A. Mendes, Carbon dioxide absorption kinetics in potassium threonate, Chem. Eng. Sci. 63 (2008) 3493-3503.

[16] Astarita, G., Savage, D. W. \& Longo, J. M. 1981. Promotion of $\mathrm{CO}_{2}$ mass transfer in carbonate solutions. Chemical Engineering Science, 36, 581-588.

[17] Thee, H., Smith, K. H., Da Silva, G., Kentish, S. E. \& Stevens, G. W. 2012. Carbon dioxide absorption into unpromoted and borate-catalyzed potassium carbonate solutions. Chemical Engineering Journal, 181, 694-701.

[18] Ye, X. \& Lu, Y. 2014. Kinetics of $\mathrm{CO}_{2}$ absorption into uncatalyzed potassium carbonatebicarbonate solutions: effects of $\mathrm{CO}_{2}$ loading and ionic strength in the solutions. Chemical Engineering Science, 116, 657-667.

[19] Tseng, P., HO, W. \& Savage, D. 1988. Carbon dioxide absorption into promoted carbonate solutions. AIChE Journal, 34, 922-931.

[20] Cullinane, J. T. \& Rochelle, G. T. 2004. Carbon dioxide absorption with aqueous potassium carbonate promoted by piperazine. Chemical Engineering Science, 59, 3619-3630.

[21] Shen, S., Feng, X., Zhao, R., Ghosh, U. K. \& Chen, A. 2013. Kinetic study of carbon dioxide absorption with aqueous potassium carbonate promoted by arginine. Chemical Engineering Journal, $222,478-487$.

[22] Cabral, J., Pantateão, I., Rodrigues, S., Catarino, M., Magalhães, F. \& Mendes, A. 2012. Kinetics of the Carbon Dioxide Absorption and Desorption with Amino Acid Salt Solutions using Hollow Fiber Membrane Contactors. Procedia Engineering, 1223-1224.

[23] Kumar, P., Hogendoorn, J., Versteeg, G. \& Feron, P. 2003. Kinetics of the reaction of $\mathrm{CO}_{2}$ with aqueous potassium salt of taurine and glycine. AIChE Journal, 49, 203-213.

[24] Aronu, U. E., Hessen, E. T., Haug-Warberg, T., Hoff, K. A. \& Svendsen, H. F. 2011b. Equilibrium absorption of carbon dioxide by amino acid salt and amine amino acid salt solutions. Energy procedia, 4, 109-116.

[25] Li, L. \& Rochelle, G. 2014. $\mathrm{CO}_{2}$ mass transfer and solubility in aqueous primary and secondary amine. Energy procedia, 63, 1487-1496.

[26] Guo, D., Thee, H., Tan, C. Y., Chen, J., Fei, W., Kentish, S., Stevens, G. W. \& Da Silva, G. 2013. Amino acids as carbon capture solvents: 6chemical kinetics and mechanism of the glycine+ $\mathrm{CO}_{2}$ reaction. Energy \& fuels, 27, 3898-3904.

[27] Portugal, A., Derks, P., Versteeg, G., Magalhaes, F. \& Mendes, A. 2007. Characterization of potassium glycinate for carbon dioxide absorption purposes. Chemical Engineering Science, 62, 65346547

[28] A. Dreimanis, J. Sediment Res, 32 (1962) 520-529.

[29] A. A. Khan, G. Halder, A. Saha, Int. J. Greenh Gas Con., 44 (2016) 217-226.

[30] Singh, P. 2011. Amine based solvent for $\mathrm{CO}_{2}$ absorption. From molecular structure to process.

[31] Adeosun, A., El hadri, N., Goetheer, E. and Abu-zahra, M. R. 2013. Absorption of $\mathrm{CO}_{2}$ by Amine Blends Solution: An Experimental Evaluation. International journal of engineering and science, 3, 1223.

[32] Thee, H. 2013. Reactive absorption of carbon dioxide into promoted potassium carbonate solvents.

[33] Todinca, T., Tănasie, C., Pröll, T. and Căta, A. 2007. Absorption with chemical reaction: evaluation of rate promoters effect on $\mathrm{CO}_{2}$ absorption in hot potassium carbonate solutions. Computer Aided Chemical Engineering. 17th European Symposium on Computer Aided Process EngineeringEscape17, Elsevier.

[34] Rinprasertmeechai, S., Chavadej, S., Rangsunvigit, P. and Kulprathipanja, S. 2012. Carbon dioxide removal from flue gas using amine-based hybrid solvent absorption. International Journal of Chemical and Biological Engineering, 6, 296-300. 
[35] Shaikh, S., Shariff, A., Bustam, M. A. and Murshid, G. 2014. Study of $\mathrm{CO}_{2}$ Solubility in Aqueous Blend of Potassium Carbonate Promoted with Glycine. Applied Mechanics \& Materials.

[36] Hu, G., Nicholas, N. J., Smith, K. H., Mumford, K. A., Kentish, S. E. and Stevens, G. W. 2016. Carbon dioxide absorption into promoted potassium carbonate solutions: A review. International Journal of Greenhouse Gas Control, 53, 28-40.

[37] Majchrowicz, M. E. 2014. Amino acid salt solutions for carbon dioxide capture.

[38] Hu, G., Smith, K. H., Wu, Y., Kentish, S. E. \& Stevens, G. W. 2017b. Screening amino acid salts as rate promoters in potassium carbonate solvent for carbon dioxide absorption. Energy \& fuels, 31, 4280-4286.

[39] Alper, E. 1990. Reaction mechanism and kinetics of aqueous solutions of 2-amino-2-methyl-1propanol and carbon dioxide. Industrial \& Engineering Chemistry Research, 29, 1725-1728.

[40] Goldberg, R. N., Kishore, N. \& LENNEN, R. M. 2002. Thermodynamic quantities for the ionization reactions of buffers. Journal of physical and chemical reference data, 31, 231-370.

[41] Bishnoi, S. \& Rochelle, G. T. 2000. Absorption of carbon dioxide into aqueous piperazine: reaction kinetics, mass transfer and solubility. Chemical Engineering Science, 55, 5531-5543.

[42] Thee, H., Nicholas, N. J., Smith, K. H., Da Silva, G., Kentish, S. E. \& Stevens, G. W. 2014. A kinetic study of $\mathrm{CO}_{2}$ capture with potassium carbonate solutions promoted with various amino acids: glycine, sarcosine and proline. International Journal of Greenhouse Gas Control, 20, 212-222.

[43] Versteeg, G. \& Van Swaaij, W. P. M. 1988. On the kinetics between $\mathrm{CO}_{2}$ and alkanolamines both in aqueous and non-aqueous solutions-I. Primary and secondary amines. Chemical Engineering Science, 43, 573-585. 